\title{
Styrylpyrone Derivative from Goniothalamus sp.: A Powerful Drug for Fighting Against Herpes Simplex Virus Type 1
}

\author{
Syaza Safia Fouzi ', Noor Zarina Abd Wahab², Leong Chee Yan', Nazlina Ibrahim ${ }^{1, *}$
}

\section{Syaza Safia Fouzi ${ }^{1}$, Noor Zarina Abd Wahab', Leong Chee Yan', Nazlina Ibrahim ${ }^{1, *}$}

'Department of Biological Science and Biotechnology, Faculty of Science and Technology, Universiti Kebangsaan Malaysia Bangi 43600, Selangor, MALAYSIA ${ }^{2}$ Department of Biomedicine, Faculty of Health Sciences, Universiti Sultan Zainal Abidin, 21300 Kuala Nerus, Terengganu, MALAYSIA

\section{Correspondence \\ Nazlina Ibrahim}

Department of Biological Science and Biotechnology, Faculty of Science and Technology, Universiti Kebangsaan Malaysia, Bangi 43600, Selangor, MALAYSIA.

E-mail: nazlina@ukm.edu.my

History

- Submission Date: 05-10-2021;

- Review completed: 29-10-2021;

- Accepted Date: 15-11-2011.

DOI : 10.5530/pj.2021.13.206

Article Available online

http://www.phcogj.com/v13/i6

Copyright

(C) 2021 Phcogj.Com. This is an openaccess article distributed under the terms of the Creative Commons Attribution 4.0 International license.

\begin{abstract}
Background: The emergence of drug resistance towards Herpes Simplex Virus Type 1 (HSV-1) has encouraged scientists to develop novel lower toxicity and highly effective anti-HSV drugs. Styrylpyrone derivative (SPD) is a bioactive compound isolated from the roots and leaves of Goniothalamus sp. It is believed that this compound possesses antiviral properties against HSV-1. Objective:This paper introduces the interaction of SPD towards HSV-1 through in silico study of molecular docking and molecular dynamic simulation. Materials and Methods: Molecular docking is a computational tool which is used to study the molecular interaction between two or more structures. ADME/T properties of the SPD were generated using the SwissADME online tool in which SPD was found to have a good pharmacokinetic profile. Results: Molecular docking study revealed that SPD has a high docking score of $-7.9 \mathrm{Kcal} / \mathrm{mol}$. SPD has a strong affinity with the thymidine kinase (PDB id: 1OF1) producing hydrogen bond and non-polar interaction at the target point of amino acid residue. Conclusion: Molecular docking analysis provides new insight into the structure-based design of SPD compounds with better antiviral activity against HSV-1.

Keywords: Antiviral, Herpes Virus type 1 (HSV-1), in silico approaches, Molecular docking and Styrylpyrone derivative.
\end{abstract}

\section{INTRODUCTION}

Human herpesvirus (HHV) from the Herpesviridae family can be classified into three subfamilies (i.e., Alpha-, Beta- and Gamma- Herpesviridae). The human herpes virus can cause mononucleosis, chickenpox, warts and cold sores. ${ }^{1}$ Herpes simplex virus classified into two types such as herpes simplex virus type- 1 and herpes simplex virus type2 (HHV-1 and HHV-2 or formerly known as HSV1 and HSV-2 respectively). Herpes simplex virus (HSV) poses double-stranded DNA and it is easily transmitted to humans through direct/indirect contact. Herpes simplex virus type 1 (HSV-1) causes oral herpes, but a proportion of HSV1 infections are genital herpes. Herpes simplex keratitis is caused by HSV-1 and it is associated with conjunctivitis too. Most patients infected with HSV do not show any clinical symptoms. ${ }^{2}$ Antiviral drugs such as Acyclovir (ACV), Valacyclovir (VCV) and Famciclovir (FCV) can be used to treat HSV infections. Unfortunately, these antiviral drugs can only alleviate the symptoms and severity of HSV infections, but not cure HSV infections. ${ }^{3}$ However, drug-resistance issues happened due to the longterm use of these antiviral drugs. ${ }^{4} \mathrm{HSV}$ resistance to $\mathrm{ACV}$ and related nucleoside analogues is due to the mutation of HSV thymidine kinase (TK) or DNA Polymerase. ${ }^{5}$ So, better antiviral drugs exhibiting lower toxicity and high effectiveness are urgently needed to meet clinical research requirements in order to combat the drug-resistant strains of HSV issues. Therefore, there is an urge to search for novel anti-HSV drugs.

Goniothalamus is the second largest genus of Annonaceae family. Goniothalamus umbrosus, locally known as kenerak, originates from the East
Coast of the Malay Peninsula. G. umbrosus is one of the most interesting and precious medicinal plants that can be served as treasure house as it poses a tremendous of pharmacological activities, such as anti-bacterial, antioxidant, anticancer and antiviral properties. ${ }^{6,7}$ Goniothalamin is a styryl-lactone found mainly in the genus Goniothalamus. It has been known to activate apoptosis in HL-60 cancer cells through the mitochondrial pathway. ${ }^{8}$ Styryl lactones from the genus Goniothalamus are secondary metabolites with either 5- or 6-membered lactones. ${ }^{9}$ Another study shown that hexane extract of G. umbrosus possess anticancer properties, apoptosis occurred in MCF7 breast cancer cells after exposure to the hexane extract. ${ }^{10}$ Apoptosis is programmed cell death, by eliminating the cells from the organism without inducing an immune response. ${ }^{11}$ Morphological changes such as shrunken cells with surface blebbing, nuclear condensation and fragmentation are signs of cell apoptosis. Styrylpyrone derivative (SPD) known as goniothalamin is a pro-apoptotic bioactive compound extracted from the roots and leaves of $G$. umbrosus.

In vitro and vivo antiviral study, SPD isolated from G. umbrosus have been claimed to possess antiviral activity against HSV-1 inducing apoptosis and cell cycle arrest during the $\mathrm{m}$ viral replication cycle. ${ }^{12,13,14}$ SPD has been proven to be effective against HSV-1 infections after 2 hours of post-infection and also reduce the yield of HSV-1. Apoptosis-inducing effect of SPD from G. umbrosus showed the apoptotic cell become shrinkage and membrane blebs. ${ }^{15} \mathrm{~A}$ high number of HSV-1 infections that threaten human health are treated using commercial antiviral drugs such as ACV, FCV and VCV, typically targeting the viral replication mode. However, existing antiviral drugs are gradually becoming ineffective for the 
treatment of HSV-1. This is because mechanisms of action of existing antiviral drugs are specifically targeting the virus as a virus can easily undergo mutation and lead to resistance towards antiviral drugs. ${ }^{16}$ As viruses direct target the host cell machinery for effective viral replication, an effective antiviral agent must prevent completion of the viral growth cycle in the virus-infected cell without being toxic to the surrounding normal cells. ${ }^{17}$

At present, SPD has proved as efficacious and safe as commercial antiviral drugs. Nevertheless, the antiviral activity of SPD was slightly lower than ACV as the ACV mechanism is directly targeting the viral DNA polymerase activity ${ }^{18}$ However, virus can easily undergo mutation and lead to resistance towards ACV and other alternatives, namely Cidofovir and Foscarnet. ${ }^{19,20}$ SPD mechanism did not directly target the virus, prompting cell cycle arrest and apoptosis in virus-infected cells. ${ }^{21}$ SPD targets the virus indirectly by activating p21 dependent cell cycle inhibition as well as p53 protein intrinsic pathway-related apoptosis. Antiviral drugs with mechanism that does not directly targeting the virus has low chances to bring about virus mutation and become resistant towards drug. ${ }^{22}$ Therefore, SPD shows very good antiviral effect against HSV-1 infection and can be classified as indirect virustargeting antiviral drugs. It reduces the virus mutation rate and avoids rapidly developing resistance.

On the other hand, SPD has shown potential anticancer activity and virucidal activity. ${ }^{23,24}$ Cancer is a scenario where less apoptosis occurs, resulting in malignant cells that will not die. ${ }^{25}$ Apoptosis is reduced when downregulation of $\mathrm{p} 53$ protein occurs, which result in enhanced tumour growth and development. The $\mathrm{p} 53$ protein is a tumour suppressor protein that helps in regulating cell division. ${ }^{26} \mathrm{An}$ elevated level of apoptosis was removed in tumours of SPD-treated rats compared to the untreated rats (control). Moreover, tumour suppressor protein p53 was more accumulated in tumour samples of SPD-treated rats. These results indicate that SPD plays the main role in up regulation of $\mathrm{p} 53$ protein expression, resulting in increased apoptosis.

\section{MATERIALS AND METHODS}

\section{Protein preparation}

Proteins used in this study are the ones that are majorly involved in the mechanism of action of the HSV-1. 3D structures of the proteins were retrieved from the Protein Data Bank (rcsb.org). DNA Uracil Glycosylase (PDB ID: 2C56), HSV-1 thymidine kinase (PDB ID: 1OF1), HSV-1 glycoprotein B (PDB ID: 6BM8) and DNA Polymerase (PDB ID: 2GV9) were used for this study. To make sure the proteins selected have good structure, only the target proteins solved by X-ray crystallography with resolution equal to or better than $3 \AA$ were used. The selected structure must also be free from mutation and modification to ensure no effect on the final protein conformation. In addition to that, Ramachandran plot analysis was used to validate the target protein structure. A good structure generally has $90 \%$ of its residues in the most favoured regions of a Ramachandran plot. The prepared protein receptors are represented in Figure 1.

\section{Ligand preparation}

Three-dimensional chemical structure of SPD (provided from www. chemspider.com) was drawn using ChemDraw3D. The prepared SPD ligand is represented in Figure 2.

\section{Molecular docking studies}

The protein-ligand binding mechanism of the HSV-1 viral protein with SPD was performed using AutoDock Vina (1.5.6 version) (Trott \& Olson 2010). SPD was docked against the 3D structure of target

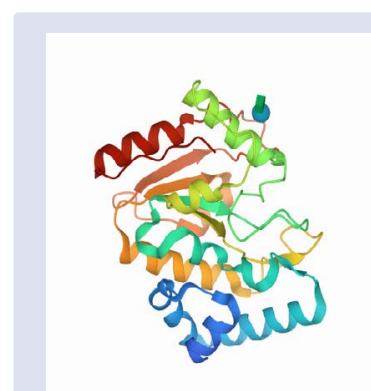

(a)

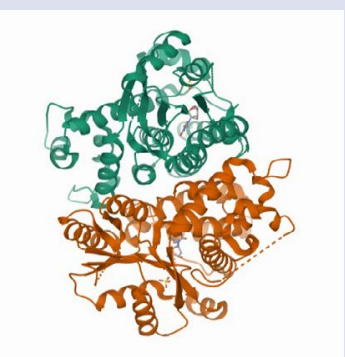

(c)

Figure 1: Prepared structure of HSV-1 target protein receptors (a) 2C56, (b) 2GV9 (c) 10F1, (d) 6BM8.

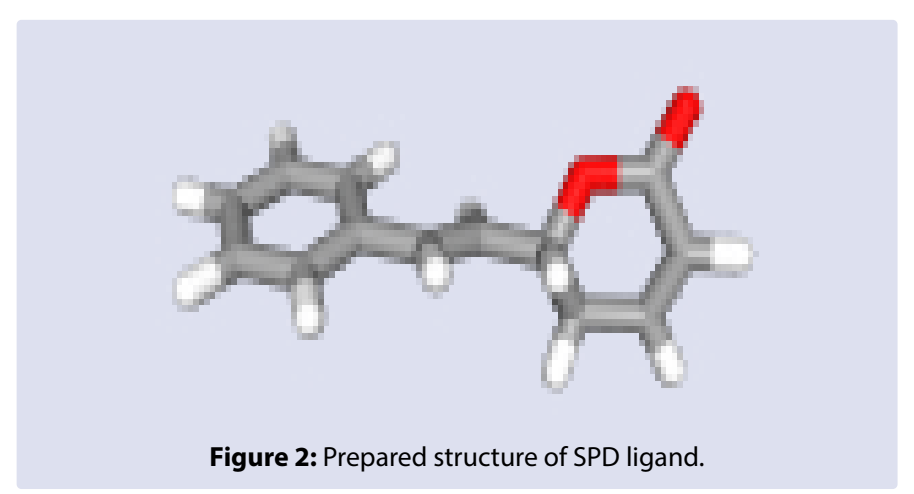

proteins by using AutoDockVina. ${ }^{27}$ The binding affinity values (kcal/ mol) of SPD to target proteins were analysed.

\section{Theoretical prediction of SwissADME parameters}

A better profile of pharmacokinetics is truly significant for a novel comparison that should be observed in the process of drug or druglike compounds discovery. Hence, it is very important to evaluate the ADMET profile of new compounds rapidly to prevent waste of resources and time. ADMET properties of SPD was predicted using SwissADME online software. ${ }^{28}$ SwissADME is a free online webserver for the insilico analysis of prediction of drug-likeness, pharmacokinetics and medicinal chemistry friendliness of small molecules, which are key determinants for more clinical trials. 2D structure of SPD compound was imported and the structure smiley format was entered at the interface of the SwissAMET website (http://www.swissadme.ch/). The SwissADME drug discovery study was run and the ADMET properties/ parameters were generated.

\section{Toxicity prediction}

Toxicity prediction of SPD was performed to check and verify the drug was safe for human use. The analyse was performed using ProToxII (February 2021 version). ProTox-II is a webserver for the in-silico prediction of oral toxicities of compounds. The 2D structure of SPD was uploaded to the server which yielded results revealing the toxicity prediction. 


\section{Carcinogenicity prediction}

Carcinogenicity prediction of SPD was performed using CarcinoPredEL (Carcinogenicity Prediction using Ensemble Learning Methods) online webserver. This webserver helps to classify compounds as carcinogens and non-carcinogens using their $2 \mathrm{D}$ structures. 2D structure of SPD compound was drawn at the interface of the CarcinoPred-EL website. The CarcinoPred-EL webserver was run and the output result was generated.

\section{RESULTS AND DISCUSSION}

\section{Toxicity prediction and ligand characteristic}

SPD act as a ligand was then subjected to drug likeliness and toxicity prediction using an online computational webserver named ProToxII. In ProTox-II, there are 6 classes for toxicity (1-6) in which class 1 has $\mathrm{LD}_{50} \leq 5$ which is toxic and lead to fatal in nature while class 6 shows $\mathrm{LD}_{50}>5000$ which means the compound is non-toxic. ${ }^{29}$ This study indicated how well and effective a drug could be with the least side effects and also informed us of a prediction score. ProTox-II prediction revealed that SPD reported with a toxicity class $\mathrm{V}$ in acute oral toxicity with a predicted $\mathrm{LD}_{50}$ value of $3400 \mathrm{mg} / \mathrm{kg}$. In ProTox-II, class $\mathrm{V}$ drugs have an $\mathrm{LD}_{50}$ value between 2000 to $5000 \mathrm{mg} / \mathrm{kg}$ and might be harmful if swallowed. $\mathrm{LD}$ stands for the lethal dose. $\mathrm{LD}_{50}$ is the dose value that causes the lethal $50 \%$ (one half) of a group of test organisms. $\mathrm{LD}_{50}$ measure the short-term poisoning potential (acute toxicity) of a compound. SPD poses an average similarity of $69.27 \%$ and prediction accuracy of $68.07 \%$. Toxicological endpoints refer to how hazardous a chemical is. Chemicals that alter the functioning of the immune system upon exposure are called immunotoxins and the adverse effect is called immunotoxicity. Chemicals that cause any cell death upon exposure are called cytotoxicants and the adverse effect is called cytotoxicity. The drug likeliness parameters with toxicity prediction and toxicity model report of SPD were displayed in Table 1 and Figure 3.
Based on Figure 3, the organ toxicity (hepatotoxicity) of SPD is predicted with a confidence score of 0.56 . SPD has potential toxicity mainly related to immunotoxicity and cytotoxicity. The toxicological endpoint (immunotoxic) of SPD is predicted active with a confidence score of 0.74 and toxicological endpoint (cytotoxic) is predicted active with a confidence score of 0.89 . Additionally, it is predicted to be inactive for both toxicological pathways. Both of these toxicological endpoints showed high probability on average $(\geq 0.70)$ and $(\geq 0.80)$ respectively. This is truly interesting, as SPD is classified under relatively less hazardous acute toxicity class (Class V); however, it has been predicted to be immunotoxic and cytotoxic at the same time. Therefore, there is a possibility that SPD compound can be active for multiple toxicity endpoints (immunotoxic and cytotoxic) and thereby resulting in severe toxic effects.

\section{Evaluation of physiochemical properties, drug-likeness, pharmacokinetics properties and medicinal chemistry friendliness of SPD}

SPD was then subjected to drug likeliness and pharmacological activity prediction using an online computational webserver named SwissADME. SwissADME prediction revealed the physiochemical properties of the SPD compounds which includes the rules of five (Molecular weight, octanol/water partition coefficient (iLOGP), number of hydrogen bond donors and number of hydrogen bond acceptors) and several other parameters/properties like topological polar surface area (TPSA), number of rotatable bonds, number of aromatic heavy atoms. The ADMET parameters with different predictions are represented in Table 2. To be an effective drug, a compound must be characterized by optimal solubility to both water and fat. Lipophilicity determines the biological processes and it is related to absorption, bioavailability, hydrophobic drug-receptor interactions, metabolism, and toxicity. Logarithm of the octanol/water partition coefficient (iLOGP), known as $\log \mathrm{P}_{\mathrm{o} / \mathrm{w}^{\prime}}$ is used to estimate solubility. ${ }^{30}$ Based on the result which

Table 1: Shortlisted SPD with drug parameters and toxicity report carried out using ProTox-II webserver.

\begin{tabular}{llllll}
\hline Compound & Structure & $\begin{array}{l}\text { Molecular } \\
\text { weight }(\mathrm{g} / \mathrm{mol})\end{array}$ & $\begin{array}{l}\text { Molar Refractivity } \\
\text { (mg/kg) }\end{array}$ & $\begin{array}{l}\text { Predicted LD } \\
\text { (mo }\end{array}$ & $\begin{array}{l}\text { Toxicity } \\
\text { class }\end{array}$ \\
Goniothalamin & 200.23 & 59.27 & 3400 & 5
\end{tabular}

\begin{tabular}{||l||}
\hline Classification \\
\hline Organ toxicity \\
\hline Toxicity end points \\
\hline Toxicity end points \\
\hline Toxicity end points \\
\hline Toxicity end points \\
\hline Tox21-Nuclear receptor signalling pathways \\
\hline Tox21-Nuclear receptor signalling pathways \\
\hline Tox21-Nuclear receptor signalling pathways \\
\hline Tox21-Nuclear receptor signalling pathways \\
\hline Tox21-Nuclear receptor signalling pathways \\
\hline Tox21-Nuclear receptor signalling pathways \\
\hline Tox21-Nuclear receptor signalling pathways \\
\hline Tox21-Stress response pathways \\
\hline Tox21-Stress response pathways \\
\hline Tox21-Stress response pathways \\
\hline Tox21-Stress response pathways \\
\hline Tox21-Stress response pathways \\
\hline
\end{tabular}

\begin{tabular}{|l|}
\hline Target \\
\hline Hepatotoxicity \\
\hline Carcinogenicity \\
\hline Immunotoxicity \\
\hline Mutagenicity \\
\hline Cytotoxicity \\
\hline Aryl hydrocarbon Receptor (AhR) \\
\hline Androgen Receptor (AR) \\
\hline Androgen Receptor Ligand Binding Domain (AR-LBD) \\
\hline Aromatase \\
\hline Estrogen Receptor Alpha (ER) \\
\hline Estrogen Receptor Ligand Binding Domain (ER-LBD) \\
\hline $\begin{array}{l}\text { Peroxisome Proliferator Activated Receptor Gamma } \\
\text { (PPAR-Gamma) }\end{array}$ \\
\hline $\begin{array}{l}\text { Nuclear factor (erythroid-derived 2)-like 2/antioxidant } \\
\text { responsive element (nrf2/ARE) }\end{array}$ \\
\hline Heat shock factor response element (HSE) \\
\hline Mitochondrial Membrane Potential (MMP) \\
\hline Phosphoprotein (Tumor Supressor) p53 \\
\hline ATPase family AAA domain-containing protein 5 (ATAD5) \\
\hline
\end{tabular}

\begin{tabular}{|l||}
\hline Shorthand \\
\hline dili \\
\hline carcino \\
\hline immuno \\
\hline mutagen \\
\hline cyto \\
\hline nr_ahr \\
\hline nr_ar \\
\hline nr_ar_lbd \\
\hline nr_aromatase \\
\hline nr_er \\
\hline nr_er_lbd \\
\hline nr_ppar_gamma \\
\hline sr_are \\
\hline sr_hse \\
\hline sr_mmp \\
\hline sr_p53 \\
\hline sr_atad5 \\
\hline
\end{tabular}

\begin{tabular}{|l|}
\hline Prediction \\
\hline Inactive \\
\hline Active \\
\hline Active \\
\hline Inactive \\
\hline Active \\
\hline Inactive \\
\hline Inactive \\
\hline Inactive \\
\hline Inactive \\
\hline Inactive \\
\hline Inactive \\
\hline Inactive \\
\hline Inactive \\
\hline Inactive \\
\hline Inactive \\
\hline Inactive \\
\hline Inactive \\
\hline
\end{tabular}

\begin{tabular}{|c|}
\hline Probability \\
\hline 0.56 \\
\hline 0.55 \\
\hline 0.74 \\
\hline 0.80 \\
\hline 0.89 \\
\hline 0.89 \\
\hline 0.98 \\
\hline 0.98 \\
\hline 0.96 \\
\hline 0.61 \\
\hline 0.98 \\
\hline 0.91 \\
\hline 0.97 \\
\hline 0.97 \\
\hline 0.86 \\
\hline 0.94 \\
\hline 0.88 \\
\hline
\end{tabular}

Figure 3: Toxicity model report of SPD. 
Table 2: Calculated ADME parameters of SPD.

\begin{tabular}{llllllll}
$\begin{array}{l}\text { Molecular } \\
\text { weight (g/ } \\
\text { mol) }\end{array}$ & $\begin{array}{l}\text { Number } \\
\text { of heavy } \\
\text { atoms }\end{array}$ & $\begin{array}{l}\text { Number of } \\
\text { aromatic } \\
\text { heavy atoms }\end{array}$ & $\begin{array}{l}\text { Number of } \\
\text { rotatable } \\
\text { bonds }\end{array}$ & $\begin{array}{l}\text { Number of } \\
\text { hydrogen } \\
\text { bond donors }\end{array}$ & $\begin{array}{l}\text { Number of } \\
\text { hydrogen } \\
\text { bond } \\
\text { acceptors }\end{array}$ & $\begin{array}{l}\text { Molar } \\
\text { refractivity }\end{array}$ & $\begin{array}{l}\text { Octanol/ } \\
\text { water partition } \\
\text { coefficient (iLOGP) }\end{array}$ \\
\hline 200.23 & 15 & 6 & 2 & 0 & 2 & 59.27 & 2.33 \\
polarea (TPSA)
\end{tabular}

Table 3: Molecular docking score of the protein and ligand complexes as obtained from in-silico molecular docking experiment done using AutoDock Vina. Binding energy values were defined in $\mathrm{kcal} / \mathrm{mol}$.

\begin{tabular}{|ccc}
\hline Protein-ligand complex & Binding Energy (kcal/mol) \\
2C56-SPD & -6.8 \\
2GV9-SPD & -5.7 \\
6BM8-SPD & -7.3 \\
1OF1-SPD & -7.9
\end{tabular}

generated from swissADME, the value of iLOGP of SPD compound is 2.33. The lipophilicity affects the penetration of bioactive molecules through a polar cell membrane, and it is a very important factor for pharmacokinetic phase. ${ }^{31}$

In pharmacokinetics, it is important to predict the skin permeability rate as this factor is vital for drugs administered via the skin. The value of skin permeability parameter using the SwissADME web server for $\mathrm{SPD}$ is $\log \mathrm{K}_{\mathrm{p}}=-5.50 \mathrm{~cm} / \mathrm{s}$. The more the negative the $\log \mathrm{K}_{\mathrm{p}}$, the less skin permeant the molecule. The molecular weight and other parameters for SPD were also found to be fitting well with the Lipinski rule of 5 for drug-likeness, no rule violation happens. All the molecular weight, number of rotatable bonds, TPSA, iLOGP, number of aromatic heavy atoms, number of hydrogen bond donors and acceptors are within the acceptable range of the ADMET properties. The lower the molecular weight, the better. A total of $80 \%$ of drugs have molecular weights lower than 450 Dalton. Therefore, we can conclude that SPD possesses a good pharmacokinetic profile.

\section{Carcinogenicity prediction}

CarcinoPred-EL revealed that SPD classified as non-carcinogen with a probability lower than 0.5 . If the probability is greater than 0.5 , the compound is known to be a carcinogen. Otherwise, it is known to be a non-carcinogenic compound. ${ }^{32}$

\section{Molecular docking studies}

SPD has been determined to possess antiviral activity against HSV1. Molecular docking performed with AutoDock Vina (1.5.6 version) further strengthen the study in searching for an effective antiviral drug against HSV-1 infection. SPD was docked successfully to all the binding sites on the target viral proteins. The drug-binding scores in the form of $\mathrm{kcal} / \mathrm{mol}$ for drugs and HSV-1 viral proteins were mentioned in Table 3.

Docking analyses and drug interactions. Based on Table 3, SPD has good binding strength to the target proteins and capable to inhibit HSV-1 virulence factors. SPD actively interact with 1 FOI protein $(-7.9 \mathrm{kcal} / \mathrm{mol})$ and $6 \mathrm{BM} 8$ protein $(-7.3 \mathrm{kcal} / \mathrm{mol})$. The analyses were performed target by target to check the efficiency of the ligand and the state of interaction using AutoDock Vina (1.5.6 version) as mentioned here below.

\section{Target 1: 1OF1 (Thymidine Kinase)}

Thymidine Kinase expression is important for the reactivation of latent HHV-1 infection. The current antiviral strategy against HHV-1 targets the viral thymidine kinase (TK) that uses ATP to phosphorylate deoxythymidine (dT), producing deoxythymidine triphosphate for DNA synthesis. Arg A: 163 residue forms hydrogen bonds with SPD ligand. TRY A:88, ALA A: 167, ALA A: 168, MET A: 128 from nonpolar interactions. The docking pose and ligand interaction diagram were displayed in Figure 4. The binding energy for this interaction was found to be $-7.9 \mathrm{kcal} / \mathrm{mol}$. This particular interaction will be significant in inhibiting the complex mechanism by which the thymidine kinase reactivates the latent HSV-1 infection.

\section{Target 2: 6BM8 (Glycoprotein B)}

Glycoprotein B is enveloped protein used in the entry of the virus into the host. Virus replication is initiated with the attachment of the virus to a receptor for entering the host. The docking result of 6BM8 with SPD revealed a docking score of $-7.3 \mathrm{kcal} / \mathrm{mol}$. Residues GLN A: 532 and ASN A: 533 form polar interactions while LEU A: 536 and TRP A: 539 form non-polar interactions. The docking pose and ligand interaction diagram were displayed in Figure 5. The interaction inhibiting the $6 \mathrm{BM} 8$ protein will help in the crucial step in the replication mechanism upon entry to the host cell.

\section{Target 3: 2 GV9 (DNA Polymerase)}

All non-polar interactions were observed. Residues TRP A: 539 and PHE A:127 participated in the SPD ligand binding. Docking pose and ligand interaction diagram were displayed in Figure 6. The binding energy obtained is $-5.7 \mathrm{kcal} / \mathrm{mol}$. This particular interaction will be significant in inhibiting the complex mechanism by which the DNA polymerase drives the replication of the virus. Most antiviral agents were being developed to combat herpesvirus infections by targeting the viral polymerase. ${ }^{33}$

\section{Target 4: 2 C56 (DNA Uracil Glycosylase)}

DNA Uracil Glycosylase (PDB id: 2C56) is an enzyme that helps in viral DNA repair and also key virulence factor of HSV-1. The docking result of 2C56 with SPD revealed a docking score of $-6.8 \mathrm{kcal} / \mathrm{mol}$. Further ligand interaction analysis reveals that SPD forms hydrogen bonds with Ser A:112. Five non-polar interactions observed were Pro A:111, Pro A: 110, Pro A: 213, Leu A: 113 and Phe A: 101. Docking pose and ligand interaction diagram were displayed in Figure 7. The mechanism of action of 2C56 which is important in viral DNA repair can successfully predicted to be inhibited with this reaction.

\section{CONCLUSION}

Computer-aided drug discovery process against the important viral proteins involved in the mechanism of action of HSV-1. Evaluation of the antiviral activity of SPD against HSV-1 was conducted successfully through in vitro, in vivo and in silico studies. SPD has shown potential activity against HSV-1 and it can be served as a second choice to treat patients with HSV-1 infection if there are no commercial drugs such as Acyclovir (ACV), Valacyclovir (VCV) and Famciclovir (FCV) available or other treatment options have been unsuccessful. And also, it can be used to replace the commercial drugs in order to overcome drug- 

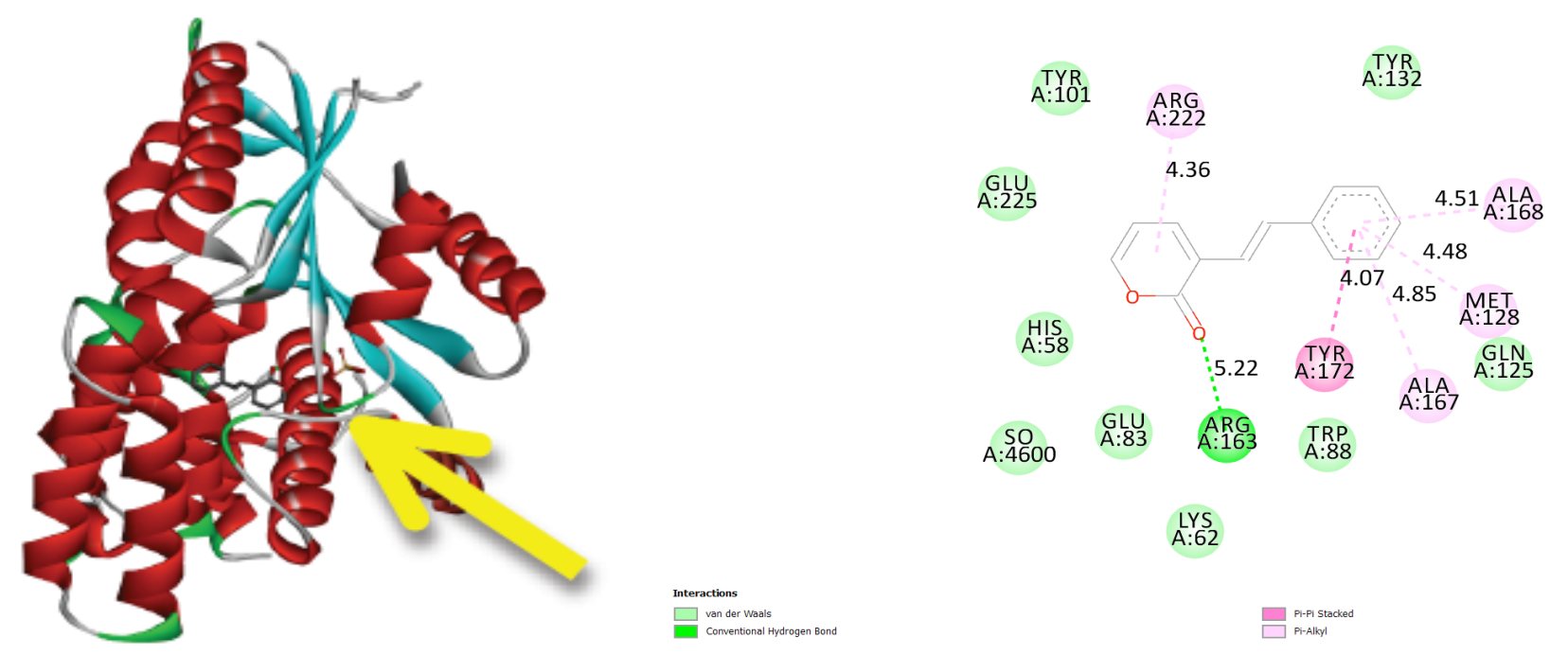

Figure 4: Docking pose (left) and Ligand interaction diagram (right) for protein-ligand interaction with 1 OF1 and SPD. The green dotted line indicates hydrogen bond interactions between 1OF1 protein and SPD ligand. The pink dotted line indicates Pi-Pi interactions between 1 OF1 protein and SPD ligand. The values adjacent to the green and pink dotted lines indicate their distance.

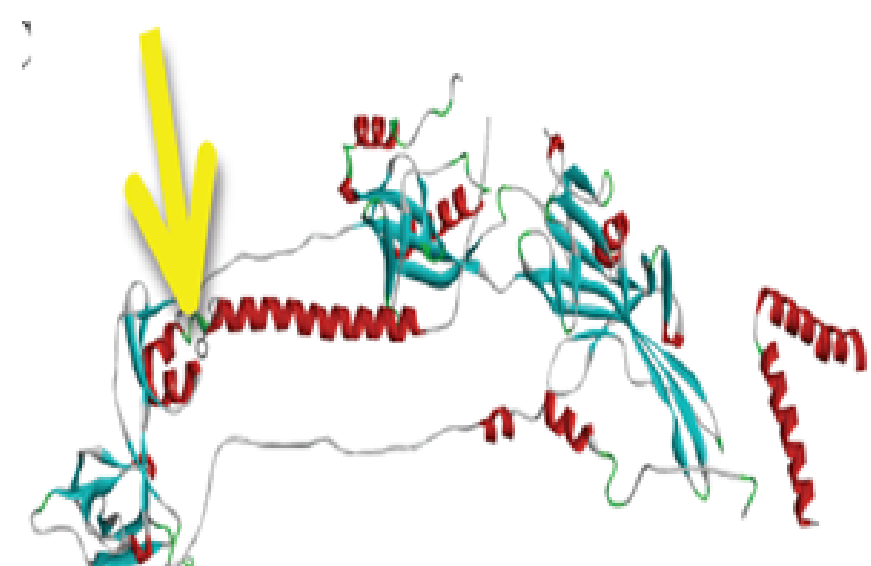

ASN

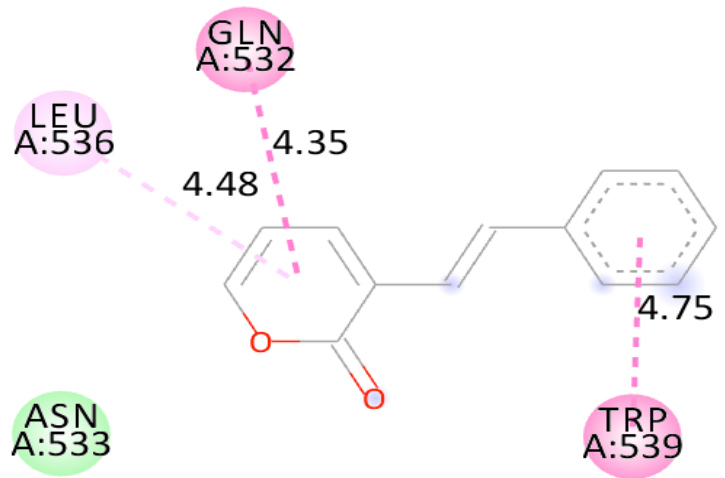

Interactions
$\square$ van der Waals

Pi Stacked

Figure 5: Docking pose (left) and Ligand interaction diagram (right) for protein-ligand interaction with 6BM8 and SPD. The green dotted line indicates hydrogen bond interactions between $6 \mathrm{BM} 8$ protein and SPD ligand. The pink dotted line indicates Pi-Pi interactions between $6 \mathrm{BM} 8$ protein and SPD ligand. The values adjacent to the green and pink dotted lines indicate their distance. 


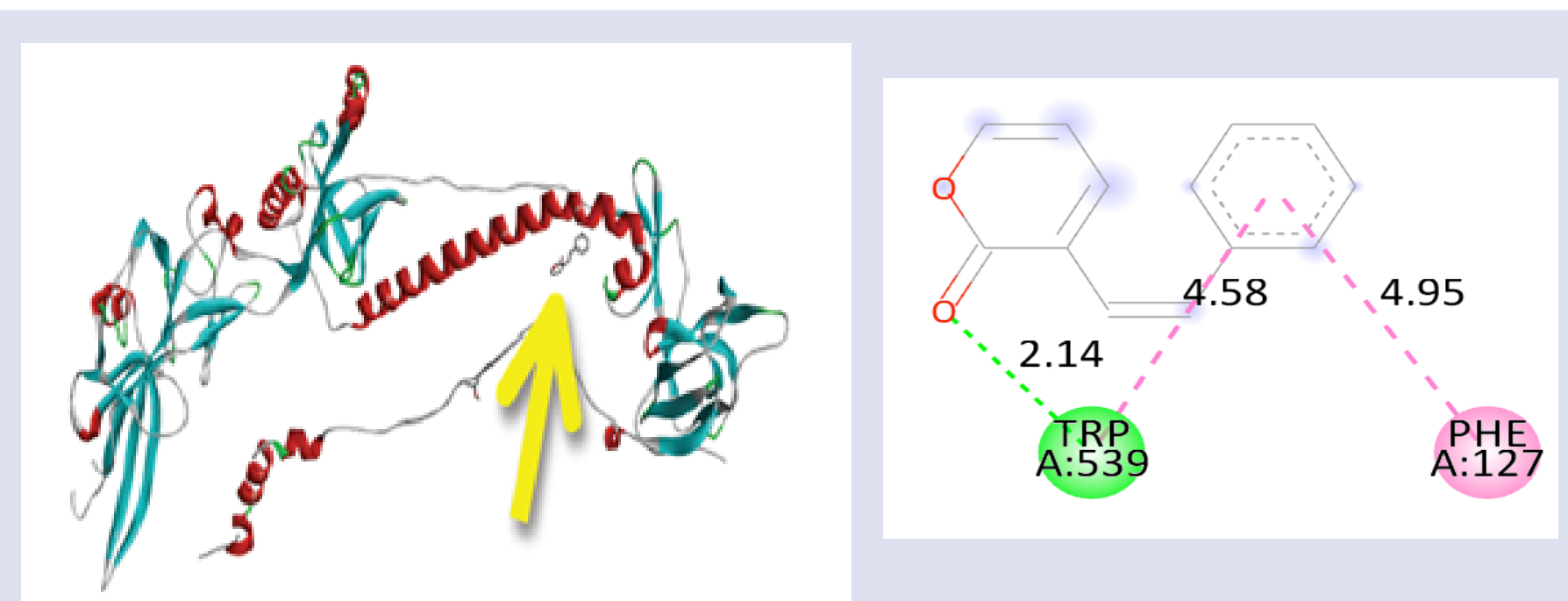

Figure 6: Docking pose (left) and Ligand interaction diagram (right) for protein-ligand interaction with 2GV9 and SPD. The green dotted line indicates hydrogen bond interactions between 2 GV9 protein and SPD ligand. The pink dotted line indicates Pi-Pi interactions between 2 GV9 protein and SPD ligand. The values adjacent to the green and pink dotted lines indicate their distance.

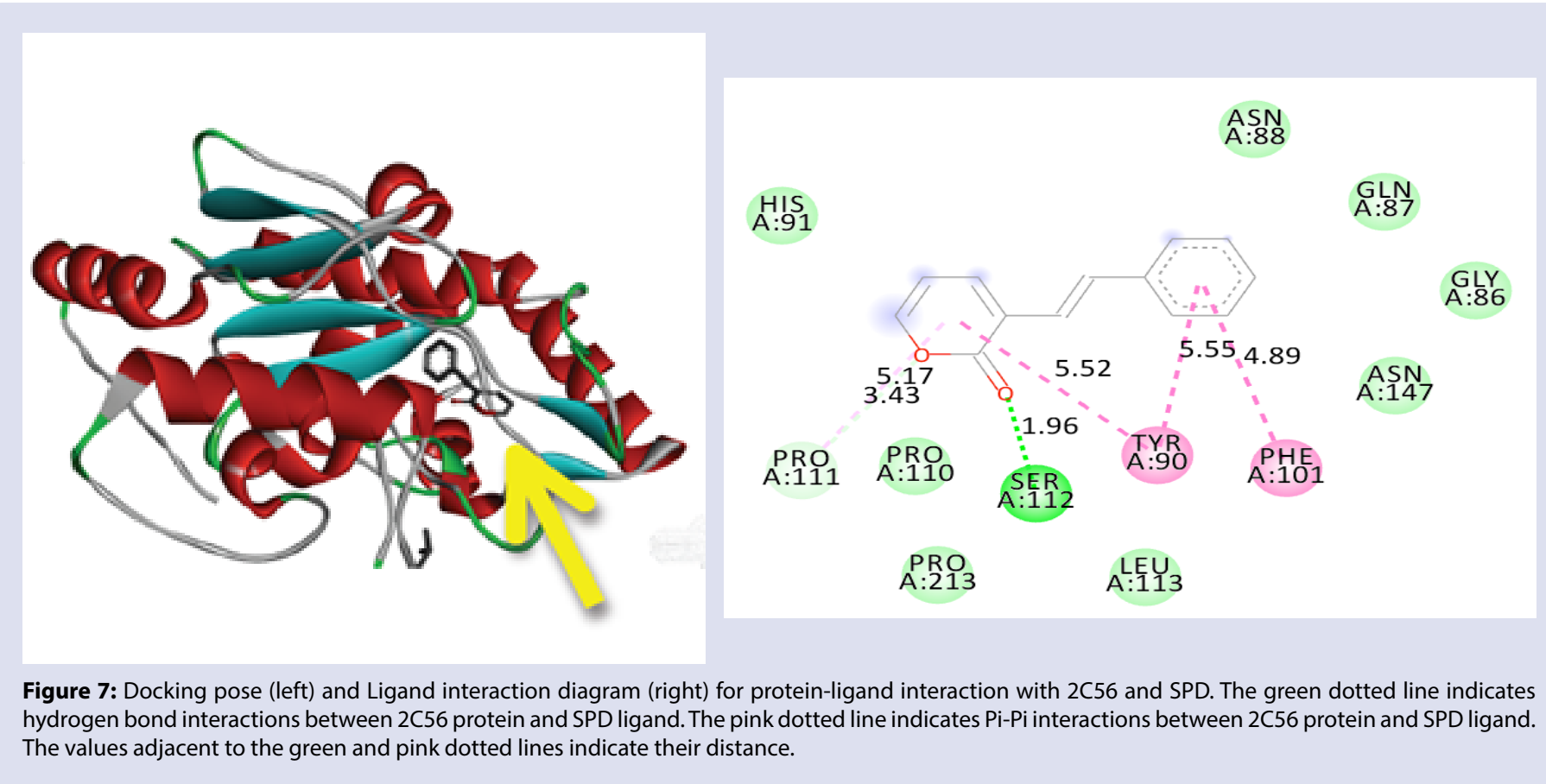

resistance issues happened. ADME/T study on SPD exhibited a good pharmacokinetics profile. SPD able to inhibit the infection of HSV-1 by targeting the correct binding site of viral protein. The result of this in silico study revealed that SPD showed good inhibitory activity against HSV-1 target viral proteins (2C56, 6BM8, 2GV9 and 1OF1). According to the docking scores, SPD displayed the highest binding affinity of -7.9 $\mathrm{kcal} / \mathrm{mol}$ against $1 \mathrm{OF} 1$ protein which is thymidine kinase. This in-silico analysis can be quickly combined with the expedited research on the experimental side to unveil the significance of SPD acting against HSV1 infection.

\section{ACKNOWLEDGMENTS}

This work was supported by Research grant of Fundamental Research Grant Scheme (FRGS), FRGS/1/2019/WAB11/UKM/02/1.

\section{REFERENCES}

1. Chattopadhyay D, Mukhopadhyay A, Ojha D, Sadhukhan P, Dutta S. Immuno-matabolic changes in herpes virus infection. Cytokine 2018 112: $52-62$.

2. Amir J, Harel L, Smetana Z, Varsano I. The natural history of primary herpes simplex type 1 gingivostomatitis in children. Pediatric Dermatology 1999; 16:259-263.

3. Arduino PG, Porter SR. Herpes simplex virus type 1 infection: overview on relevant clinico-pathological features. Journal of Oral Pathology and Medicine 2007; 37:107-121.

4. Toriyama K, Inoue T, Suzuki T, Kobayashi T, Ohashi Y. Necrotizing keratitis caused by acyclovir-resistant herpes simplex virus. Case Report in Ophthalmology, 2014; 5(3):325-328. 
5. Khan MTH, Ather A, Thompson KD, Gambari R. Extracts and molecules from medicinal plants against herpes simplex viruses. Antiviral Research 2005; 67 (2005): 107-109.

6. Wiart C. 2007. Goniothalamus species: A source of drugs for the treatment of cancers and bacterial infections? Evidence-Based Complementary and Alternative Medicine 2007; 4(3):299-311.

7. Abdul Wahab NZ, Shahar S, Abdullah Sani H, Lope Pihie AH, Ibrahim N. Antioxidant, antibacterial and antiviral properties of Goniothalamus umbrosus leaves methanolic extract. African Journal of Microbiology Research, 2011; 5(20): 3138-3143.

8. Inayat-Hussain SH, Chan KM, Rajab NF, Din LB, Chow SC, Kizilors A, Farzaneh F, Williams GT. Goniothalamin-induced oxidative stress, DNA damage and apoptosis via caspase-2 independent and $\mathrm{Bcl}-$ 2 independent pathways in Jurkat T-cells. Toxicology Letters 2010; 193(1):108-114

9. de Fatima A, Modolo LV, Conegero LS, Pilli RA, Ferreira CV, Kohn LK, de Carvalho JE. Styryl lactones and their derivatives: biological activities, mechanisms of action and potential leads for drug design. Current Medicinal Chemistry 2006; 13:3371-3384.

10. Abdelwahab SI, Abdul AB, Elhassan MM, Mohan S, Al-zubairi AS, ALHaj NA, Abdullah R, Mariod AA. Biological and phytochemical investigations of Goniothalamus umbrosus leaves hexane extract. Journal of Medicinal Plants Research 2009; 3(11): 880-885.

11. Wong RS. Apoptosis in cancer: from pathogenesis to treatment. Journal of Exp Clin Cancer Res. 2011; 30: 87.

12. Abd Wahab NZ, Ibrahim N. in vitro study, antiviral activity of styrylpyrone derivative against dengue virus type 2 . Asian Journal of Plant Sciences, 2020; 19(4): 438-442.

13. Bahtiar AA, Md Nor NS, Ibrahim N. In vitro antiviral activity of styrylpyrone derivative-incorporated formulations against Herpes simplex virus type-1. Malaysian Journal of Microbiology 2016; 12(3): 228-232.

14. Md Nor NS, Ibrahim N. Styrylpyrone derivative of Goniothalamus umbrosus inhibit HSV-1 infection during viral early replication cycle. Antiviral Research 2011; 90, A21-A78.

15. Md Nor N, Ibrahim N. Styrylpyrone derivative (SPD) induce cell cycle arrest during Herpes Simplex Virus type-1 (HSV-1) infection. International Journal of Infectious Diseases 2012; 16(6): 97.

16. Irwin KK, Renzette N, Kowalik TF, Jensen JD. Antiviral drug resistance as an adaptive process. Virus Evolution 2016; 2(1): vew014.

17. Julia $M$, Leevi $K$, Tero, $A$. Inhibitors of virus replication: recent developments and prospects. Appl Microbiol Biotechnol 2005; 66(6), 612-621.

18. van de Sand L, Bormann M, Schmitz Y, Heilingloh CS, Witzke O, Krawczyk A. Antiviral Active Compounds Derived from Natural Sources against Herpes Simplex Viruses. Viruses 2021; 13(7): 1386.
19. Griffiths A. Slipping and sliding: Frameshift mutations in herpes simplex virus thymidine kinase and drug-resistance. Drug Resistance Updates 2011; 14(6), 0-259.

20. Sauerbrei A, Deinhardt S, Zell R, Wutzler P. Testing of herpes simplex virus for resistance to antiviral drugs. Virulence 2010; 1(6): 555-557.

21. Md Nor NS. Antiviral mechanism of styrylpyrone derivative (SPD) compound from Goniothalamus umbrosus against Herpes Simplex Virus type-1. Ph.D Thesis, Universiti Kebangsaan Malaysia, Malaysia. 2015.

22. Strasfeld L, Chou S. Antiviral drug resistance: Mechanisms and clinical implications. Infectious Disease Clinics of North America 2010; 24(2): 413-437.

23. Meenakshii N, Lee A, Azimahtol Hawariah LP, Hasidah S. Increased Levels of Apoptosis Correlate with p53 Protein Accumulation in Response to the Styrylpyrone Derivative (SPD) Treatment of the 'Huggins Tumour'. Malays Appl Biol 2000; 29: 121-126.

24. Moses M, Md Nor NS, Ibrahim N. In vitro virucidal activity of styrylpyrone derivative against herpes simplex virus KOS-1. AIP Conference Proceedings 2014; 1614, 562-565.

25. Wong RSY. Apoptosis in cancer: from pathogenesis to treatment Journal of Experimental \& Clinical Cancer Research, 2011; 30(1): 87.

26. Fridman J, Lowe S. Control of apoptosis by p53. Oncogene 2003; $22,9030-9040$

27. Trott O, Olson AJ. AutoDock Vina: improving the speed and accuracy of docking with a new scoring function, efficient optimization and multithreading. J Comput Chem 2010; 31(2): 455-461.

28. Daina A, Michielin O, Zoete V. SwissADME: a free web tool to evaluate pharmacokinetics, drug-likeness and medicinal chemistry friendliness of small molecules. Sci. Rep. 2017; 7: 42717.

29. Banerjee P, Eckert AO, Schrey AK, Preissner R. ProTox-II: a webserver for the prediction of toxicity of chemicals. Nucleic Acids Research 2018; 1-7.

30. Kovačević SZ, Jevrić LR, Podunavac Kuzmanović SO, Lončar ES Prediction of In-silico ADME Properties of 1,2-O-Isopropylidene Aldohexose Derivatives. Iran J Pharm Res. 2014; 13(3): 899-907.

31. Podunavac KS, Cvetković D. Lipophilicity and antifungal activity of some 2-substituted benzimidazole derivatives. Chemical Industry and Chemical Engineering Quarterly 2011; 17(1), 9-15.

32. Li Z, Haixin A, Wen C, Zimo Y, Huan H, Junfeng Z, Jian Z, Qi Z, Hongsheng L. CarcinoPred-EL: Novel models for predicting the carcinogenicity of chemicals using molecular fingerprints and ensemble learning methods. Scientific reports 2017; 7: 2118.

33. Weller SK, Coen DM. Herpes simplex viruses: mechanisms of DNA replication. Cold Spring Harb Perspect Biol 2012 4(9): a013011. 


\section{GRAPHICAL ABSTRACT}
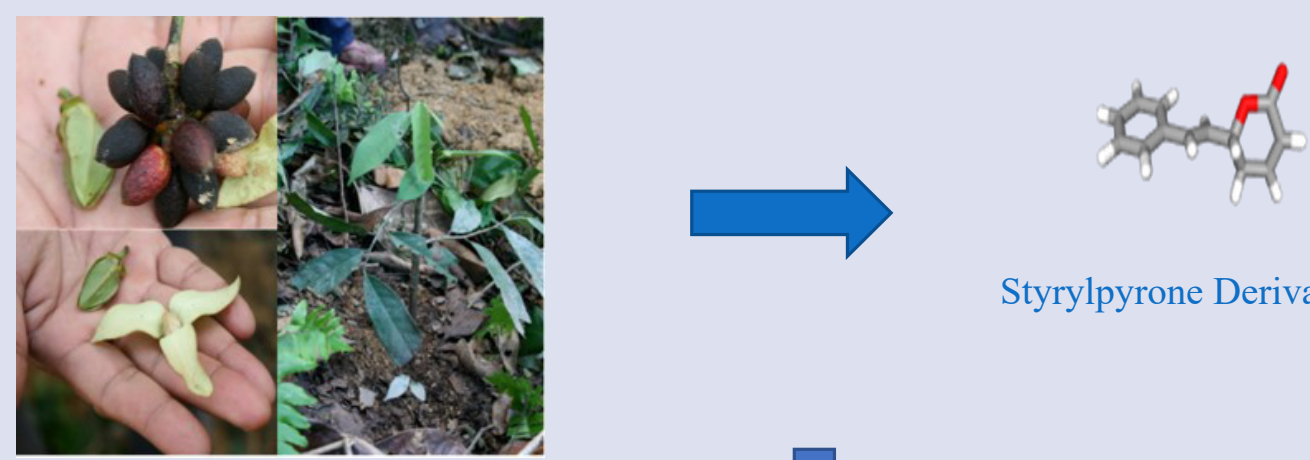

Styrylpyrone Derivatives (SPD)

Goniothalamus umbrosus

Methods: Molecular docking and molecular dynamic simulation

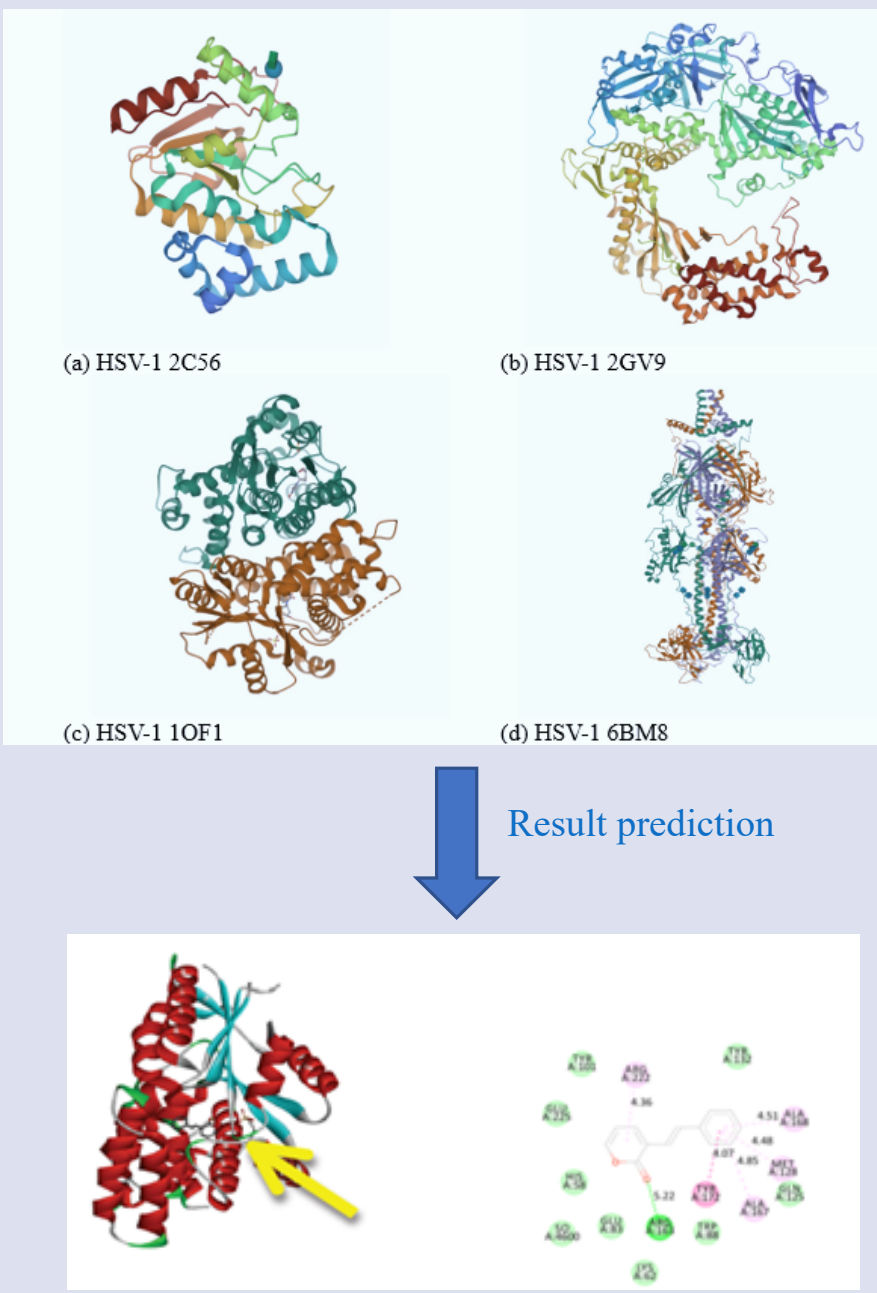

SPD has highest docking score of $-7.9 \mathrm{Kcal} / \mathrm{mol}$. SPD has strong affinity with the thymidine kinase (PDB id: 1OF1) producing hydrogen bond and non-polar interaction at the target point of amino acid residue 


\section{ABOUT AUTHORS}

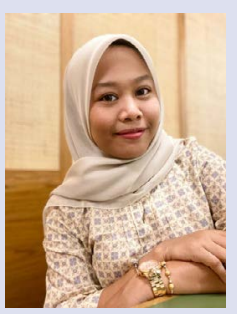

Syaza Safia Fouzi graduated with a Microbiology degree from Universiti Kebangsaan Malaysia. She was involved in in silico determination of anti-dengue virus and anti-herpes simplex virus activity of plant compounds. She currently researched on the mighty probiotics, especially in the administration of probiotics to aquaculture system.

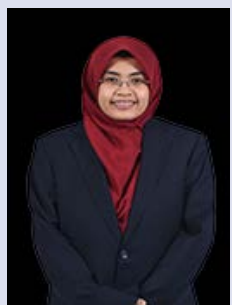

Dr. Noor Zarina Abd Wahab is senior lecturer at the Department of Biomedicine, Faculty of Health Sciences, Universiti Sultan Zainal Abidin, Malaysia. Her current research interest is antimicrobial mechanism of action and biological activity of plant natural products.

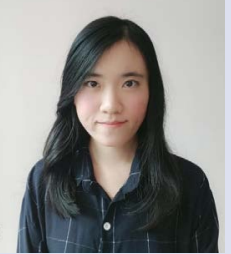

Leong Chee Yan graduated from Universiti Kebangsaan Malaysia in year 2019 with bachelor's degree in Microbiology. Her academic experience involved understanding in vitro and in silico plant antiviral activity. She currently works as tutor in a tuition center with interest in pursuing in postgraduate studies.

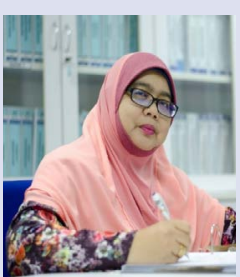

Dr. Nazlina Ibrahim is senior lecturer at the Department of Biological Sciences and Biotechnology, Faculty of Science and Technology, Universiti Kebangsaan Malaysia. Her current research interest is understanding anti-microbial activities of plants, endophytes and synthetic chemicals. Her main focus is in the development of antiviral products from local plants.

Cite this article: Fouzi SS, Abd Wahab, NZ, Yan LC, Ibrahim N. Styrylpyrone Derivatives from Goniothalamus sp.: A Powerful Drug for Fighting Against Herpes Simplex Virus Type 1. Pharmacogn J. 2021;13(6)Suppl: 1598-1606. 